\title{
Communication
}

\section{A New Lyngbyatoxin from the Hawaiian Cyanobacterium Moorea producens}

\author{
Weina Jiang ${ }^{1}$, Wei Zhou ${ }^{1}$, Hajime Uchida ${ }^{1}$, Masayuki Kikumori ${ }^{2}$, Kazuhiro Irie ${ }^{2}$, \\ Ryuichi Watanabe ${ }^{3}$, Toshiyuki Suzuki ${ }^{3}$, Bryan Sakamoto ${ }^{4}$, Michiya Kamio ${ }^{1}$ and \\ Hiroshi Nagai ${ }^{1, *}$
}

1 Department of Ocean Sciences, Tokyo University of Marine Science and Technology, Tokyo 108-8477, Japan; E-Mails: jwnkouina@gmail.com (W.J.); vivitalot@gmail.com (W.Z.); huchida.msr181823@gmail.com (H.U.); mkamio@kaiyodai.ac.jp (M.K.)

2 Division of Food Science and Biotechnology, Graduate School of Agriculture, Kyoto University, Kyoto 606-8502, Japan; E-Mails: kikumori@kais.kyoto-u.ac.jp (M.K.); irie@kais.kyoto-u.ac.jp (K.I.)

3 National Research Institute of Fisheries Science, Yokohama 236-8648, Japan; E-Mails: rwatanabe@affrc.go.jp (R.W.); tsuzuki@affrc.go.jp (T.S.)

4 Richard L. Roudebush VA Medical Center, Indianapolis, IN 46202, USA; E-Mail: bryan.sakamoto@va.gov

* Author to whom correspondence should be addressed; E-Mail: nagai@kaiyodai.ac.jp; Tel./Fax: +81-3-5463-0454.

Received: 17 February 2014; in revised form: 6 April 2014 / Accepted: 8 April 2014 / Published: 12 May 2014

\begin{abstract}
Lyngbyatoxin A from the marine cyanobacterium Moorea producens (formerly Lyngbya majuscula) is known as the causative agent of "swimmer's itch" with its highly inflammatory effect. A new toxic compound was isolated along with lyngbyatoxin A from an ethyl acetate extract of M. producens collected from Hawaii. Analyses of HR-ESI-MS and NMR spectroscopies revealed the isolated compound had the same planar structure with that of lyngbyatoxin $\mathrm{A}$. The results of optical rotation and $\mathrm{CD}$ spectra indicated that the compound was a new lyngbyatoxin A derivative, 12-epi-lyngbyatoxin A (1). While 12-epi-lyngbyatoxin A showed comparable toxicities with lyngbyatoxin A in cytotoxicity and crustacean lethality tests, it showed more than 100 times lower affinity for protein kinase $\mathrm{C} \delta(\mathrm{PKC} \delta)$ using the $\mathrm{PKC} \delta$ - $\mathrm{C} 1 \mathrm{~B}$ peptide when compared to lyngbyatoxin A.
\end{abstract}


Keywords: lyngbyatoxin A; cyanobacteria; Moorea producens; toxicity; protein kinase C

\section{Introduction}

Moorea producens (formerly classified as Lyngbya majuscula) [1] a filamentous marine cyanobacterium can cause human skin irritation (seaweed dermatitis) known as "swimmer's itch" [2]. The causative agents of "swimmer's itch" have been reported to be lyngbyatoxin A, aplysiatoxin and their derivatives, which are produced by M. producens [3-5]. These toxins have been shown to possess potent tumor-promoting activity and ability to activate protein kinase $\mathrm{C}$ isozymes [6,7]. Fatal intoxication due to ingestion of lyngbyatoxin A contaminated flesh of the turtle Chelonia mydas has been reported [8,9]. In addition, aplysiatoxin and related toxins were revealed to be the causative agents of food poisoning by the red alga Gracilaria coronopifolia [10-12]. The true producer of these toxins involved in these poisoning cases was deduced to be $M$. producens $[8,10]$. Since these toxins produced by $M$. producens are suspected as fatal tumor-causing factors for marine animals, such as the green turtle and manatee $[13,14]$, the study of toxins produced by $M$. producens is important from an ecotoxicological point of view. Additionally, M. producens is a rich source of unique compounds which has led to the extensive study of its bioactive compounds, that may lead to the discovery of novel therapeutics agents [15-17]. We examined the toxic components in the extracts of $M$. producens collected from Hawaii guided by the lethal activity toward crustaceans. A new lyngbyatoxin derivative (1, 12-epi-lyngbyatoxin A, Figure 1) was isolated along with lyngbyatoxin A (2, Figure 1). In this report, the isolation, structure and toxicities of compound $\mathbf{1}$ will be discussed.

Figure 1. Structures of compounds 1-5.

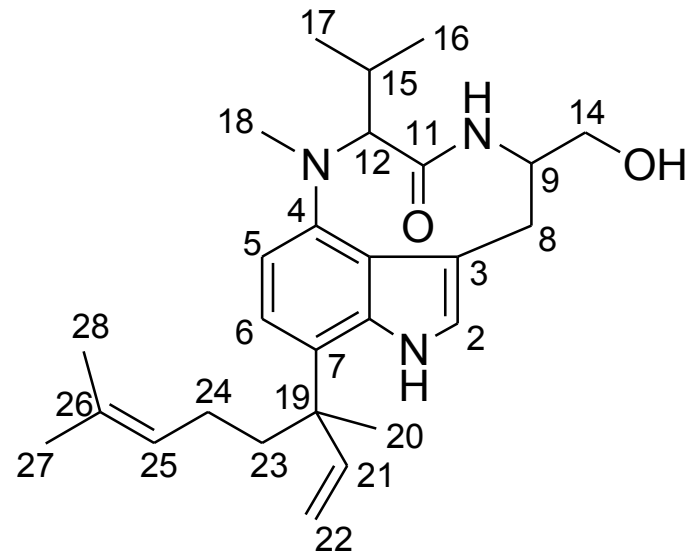

1: 12-Epi-lyngbyatoxin A $(9 S, 12 R, 19 R) ; 2$ : Lyngbyatoxin A (teleocidin A-1) $(9 S, 12 S, 19 R)$;

3: Teleocidin A-2 $(9 S, 12 S, 19 S)$; 4: Enantiomer of $2(9 R, 12 R, 19 S)$; $\mathbf{5}$ : Enantiomer of $\mathbf{3}(9 R, 12 R, 19 R)$.

\section{Results and Discussion}

Compounds $\mathbf{1}$ and $\mathbf{2}$ were both isolated as pale yellow gummy solids. Compound $\mathbf{2}$ was identified to be lyngbyatoxin A which had been first isolated from the Hawaiian cyanobacterium [3]. HR-ESI-MS of compound 1 exhibited a molecular ion peak at $m / z 438.3070[\mathrm{M}+\mathrm{H}]^{+}$, consistent with the molecular 
formula of $\mathrm{C}_{27} \mathrm{H}_{39} \mathrm{~N}_{3} \mathrm{O}_{2}$, which was the same molecular formula with that of lyngbyatoxin $\mathrm{A}$ (2). The presence of an indole ring was suggested from its UV spectrum $\left(\lambda_{\max }(\mathrm{EtOH}) \mathrm{nm}(\log \varepsilon) 231\right.$ (4.33), 301 (3.86)) comparing with that of 2.

Comparison of the ${ }^{1} \mathrm{H}$ and ${ }^{13} \mathrm{C}$ NMR data of 1 with those of 2 , together with $2 \mathrm{D}$ NMR spectral analysis led us to elucidate the planar structure of the new compound as $\mathbf{1}$ (Figure 2). The planar structure of 1 was completely the same as that of lyngbyatoxin $\mathrm{A}(2) .{ }^{1} \mathrm{H}$ and ${ }^{13} \mathrm{C}$ NMR spectral data for 1 were shown in Table 1 . On ${ }^{1} \mathrm{H}$ NMR, most of the chemical shifts of $\mathbf{1}$ were closely similar to those of 2 (see Supplementary Information, Table S1). However, some proton chemical shifts (for example, H-9, H-12 and H-14) on a nine-membered lactam ring were somewhat different from those of $\mathbf{2}$. From these observations, 1 was deduced to have the same planar structure with 2. However, the absolute configuration around the nine-membered lactam ring appeared to be different between 1 and 2.

Figure 2. Key correlations of compound $\mathbf{1}$ in the COSY (bold line) and HMBC (arrow) spectra.
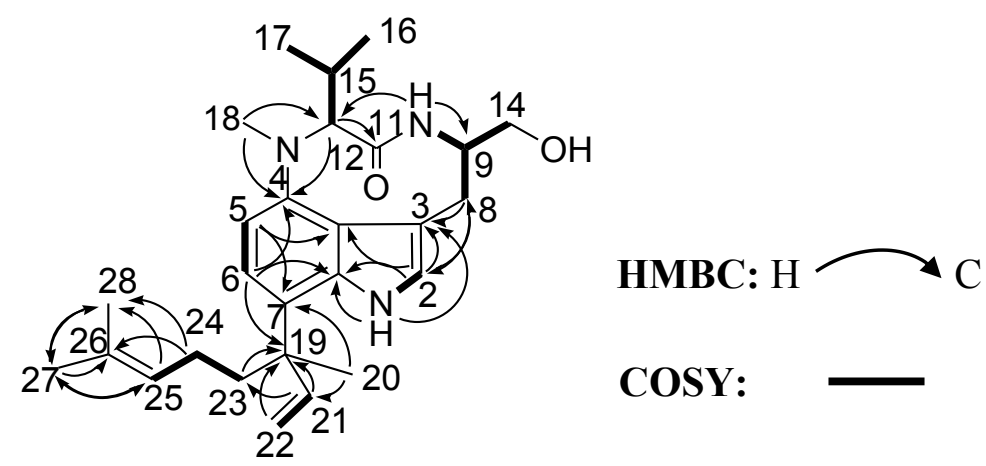

\section{COSY:}

Lyngbyatoxin A (2) was first isolated as the causative agent of seaweed dermatitis from the cyanobacterium [3]. Later lyngbyatoxin A was found to be identical to teleocidin A-1 (2), the toxic metabolite from the actinomycete Streptomyces mediocidicus [18]. Teleocidin A-2 (3, Figure 1) of which C-19 had $S$ configuration was also reported from $S$. mediocidicus [18]. The only structural difference between 2 and $\mathbf{3}$ was the configuration on C-19 in the linalyl group side chain. The circular dichroism (CD) spectra of compounds 2 and $\mathbf{3}$ showed only difference at around $230 \mathrm{~nm}$ (see Supplementary Information, Figure S22) [19,20]. The CD spectra around $230 \mathrm{~nm}$ of 2 and $\mathbf{3}$ showed upward and downward curves, respectively. Furthermore, CD spectra around $230 \mathrm{~nm}$ of 4 and 5 (synthesized compounds, Figure 1) showed downward and upward curves, respectively (see Supplementary Information, Figure S22) [20]. These results indicated the absolute configurations on $\mathrm{C}-19$ of the linalyl group in lyngbyatoxin A derivatives were defined around $230 \mathrm{~nm}$ (CD spectra) as $19-R$ and $19-S$ configurations which resulted in upward and downward curves, respectively. CD spectra of 1 and $\mathbf{2}$ were shown in Figure 3. Both compounds showed upward curves around $230 \mathrm{~nm}$, indicated that compound $\mathbf{1}$ had the same absolute configuration $R$ at $\mathrm{C}-19$ with that of $\mathbf{2}$. In addition, the CD spectra of compounds 2 and 5 showed differences at around $220 \mathrm{~nm}$ and $270 \mathrm{~nm}$. The spectra around $220 \mathrm{~nm}$ and $270 \mathrm{~nm}$ of compound $\mathbf{2}$ showed both downward curves, while compound $\mathbf{5}$ showed both upward curves. The same spectral tendencies were observed in compounds $\mathbf{3}$ and $\mathbf{4}$ (see Supplementary Information, Figure S22) [20]. The both upward curves at 220 and $270 \mathrm{~nm}$ meant C-9 
$(R)$ and C-12 $(R)$, while both downward curves meant C-9 $(S)$ and C-12 $(S)$. On the other hand, the CD spectra of compound 1 showed upward curve at $220 \mathrm{~nm}$ and downward curve at $270 \mathrm{~nm}$. The results indicated that compound 1 had $9 S, 12 R$ or $9 R, 12 S$ configurations. Taking this into consideration, it was supposed that the absolute configurations of compound 1 were $9 S, 12 R, 19 R$ or $9 R, 12 S, 19 R$.

Table 1. NMR spectroscopic data for compound 1 in $\mathrm{CDCl}_{3}$.

\begin{tabular}{|c|c|c|c|}
\hline No. & $\delta_{C}{ }^{a}$ & $\delta_{\mathrm{H}}(J \text { in } \mathrm{Hz})^{b}$ & НМВС \\
\hline 1 & & $8.45, \mathrm{~s}$ & $3,3 a, 7 a$ \\
\hline 2 & 121.8 & $6.81, \mathrm{~d}(1.9)$ & $3,3 a, 7 a, 8$ \\
\hline 3 & 113.8 & & \\
\hline $3 a$ & 120.9 & & \\
\hline 4 & 146.7 & & \\
\hline 5 & 109.0 & $6.73, \mathrm{~d}(8.1)$ & $3,3 a, 4,7$ \\
\hline 6 & 119.8 & $6.95, \mathrm{~d}(8.1)$ & $4,5,7 \mathrm{a}, 19$ \\
\hline 7 & 122.7 & & \\
\hline $7 \mathrm{a}$ & 136.6 & & \\
\hline \multirow[t]{2}{*}{8} & 32.3 & $3.27, \mathrm{dd}(15.6,2.5)$ & $2,3,4,9,14$ \\
\hline & & $2.90, \mathrm{dd}(15.6,2.5)$ & \\
\hline 9 & 57.6 & $3.84, \mathrm{br}, \mathrm{m}$ & \\
\hline 10 & & $7.45, \mathrm{br}, \mathrm{s}$ & $9,12,14$ \\
\hline 11 & 175.2 & & \\
\hline 12 & 69.0 & $3.91, \mathrm{~d}(10.6)$ & $4,11,15,17$ \\
\hline \multirow[t]{2}{*}{14} & 65.4 & 3.88 , dd $(10.4,3.6)$ & 8,9 \\
\hline & & $3.82, \mathrm{dd}(10.4,6.5)$ & \\
\hline 15 & 28.1 & $2.61, \mathrm{~m}$ & $12,16,17$ \\
\hline 16 & 20.0 & $0.67, \mathrm{~d}(6.6)$ & $12,15,17$ \\
\hline 17 & 20.4 & $0.74, \mathrm{~d}(6.5)$ & $12,15,16$ \\
\hline 18 & 31.6 & $3.09, \mathrm{~s}$ & 4,12 \\
\hline 19 & 43.4 & & \\
\hline 20 & 24.7 & $1.44, \mathrm{~s}$ & $7,19,21,23$ \\
\hline 21 & 148.8 & $6.21, \mathrm{dd}(17.7,10.6)$ & $7,19,23$ \\
\hline \multirow[t]{2}{*}{22} & 112.2 & $5.29, \mathrm{dd}(17.9,1.4)$ & 19,21 \\
\hline & & $5.26, \mathrm{dd}(10.7,1.4)$ & \\
\hline \multirow[t]{2}{*}{23} & 38.2 & $1.98, \mathrm{~m}$ & $7,19,21,24,25$ \\
\hline & & $1.81, \mathrm{~m}$ & \\
\hline \multirow[t]{2}{*}{24} & 22.7 & $1.91, \mathrm{br}, \mathrm{m}$ & $23,25,26,28$ \\
\hline & & $1.71, \mathrm{br}, \mathrm{m}$ & \\
\hline 25 & 124.6 & $5.08, \mathrm{t}(7.1)$ & $23,24,27,28$ \\
\hline 26 & 131.5 & & \\
\hline 27 & 17.4 & $1.40, \mathrm{~s}$ & $25,26,28$ \\
\hline 28 & 25.7 & $1.64, \mathrm{~s}$ & $25,26,27$ \\
\hline $\mathrm{OH}$ on 14 & & Not observed & \\
\hline
\end{tabular}

${ }^{\text {a }}$ Recorded at $200 \mathrm{MHz}$; ${ }^{\mathrm{b}}$ Recorded at $800 \mathrm{MHz}$. Coupling constants (Hz) are in parentheses. Abbreviations: s, singlet; d, doublet; t, triplet; m, multiplet; br, broad. 
Figure 3. CD spectra of compounds 1 and 2.

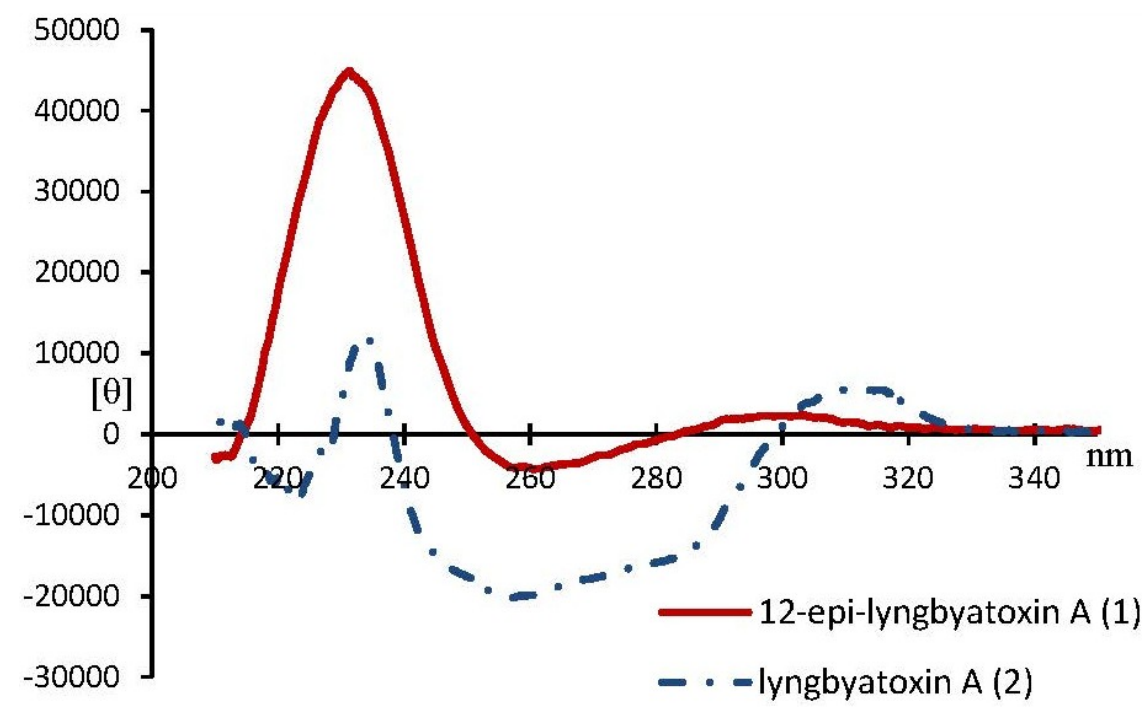

The ${ }^{1} \mathrm{H}$ NMR spectrum of 2 in $\mathrm{CDCl}_{3}$ showed that it existed as a mixture of trans and cis amide conformers. The conformational ratio of lyngbyatoxin A was about 1:3 (trans:cis) (see Supplementary Information, Figure S24). This conformational ratio was almost the same as that of (-)-indolactam-V (IL-V, 6, Figure 4) [21,22], which is regarded to be a core structure exhibiting tumor-promoting activity of teleocidins (lyngbyatoxins) [23]. IL-V (6), which has chiral carbon centers at C-9 and C-12 with the configurations of $S$ and $S$, is a partial structure of 2 . Therefore, the enantiomer $(9 R, 12 R)$ of IL-V should also exist as two conformers of which the ratio is about 1:3 (trans:cis) in $\mathrm{CDCl}_{3}$. In this study, it was shown that compound $\mathbf{1}$ had nearly one conformer on the ${ }^{1} \mathrm{H}$ NMR spectrum (see Supplementary Information, Figure S23). It was reported that (+)-epi-IL-V $(9 S, 12 R)$ should have more than two conformers by the computational calculations [24]. However, it had been shown that the main conformation was dominant for $(+)$-epi-IL-V $(9 S, 12 R)$ on the ${ }^{1} \mathrm{H}$ NMR spectrum as in the case of compound 1 [21,24]. Therefore, the absolute configurations at C-9 and C-12 in the new lyngbyatoxin derivative (1) were inferred to be $S$ and $R$ or $R$ and $S$, respectively, which further certified the conclusion drawing from the analyses of the CD spectra.

IL-V (6) and a number of related compounds have been isolated from natural samples or synthesized [3,18-20,25-33]. Those reports showed that all the reported compounds containing 6 $(9 S, 12 S)$ so far had levorotatory optical rotations no matter what the terpene group was connected to the indole ring (see Supplementary Information, Figures S26 and S27). However, we should pay attention that the levorotatory optical rotation of IL-V is determined not only by the $9 S, 12 S$ configuration, but also by the main conformer of cis amide in the solution [30,34]. The synthetic IL-Vs $(9 S, 12 S)$ and $(9 R, 12 S)$ showed levorotatory optical rotation while IL-Vs $(9 R, 12 R)$ and $(9 S, 12 R)$ had dextrorotatory optical rotation (see Supplementary Information, Figures S26 and S27) [26,28]. Since the optical rotation of $\mathbf{1}$ was dextrorotatory, the configurations of indolactam (IL-V) of $\mathbf{1}$ were deduced to be $9 R, 12 R$ or $9 S, 12 R$. Moreover, the absolute configurations at C-9 and C-12 in compound 1 were inferred to be $9 S, 12 R$ or $9 R, 12 S$ from the results of $C D$ analysis. The absolute configuration of C-19 has been deduced as $R$ also from CD spectra. When taken these results together, it was deduced that compound 1 had $9 S, 12 R, 19 R$ absolute configurations. Furthermore, the deduced absolute chemistry of 
indolactam of $1(9 S, 12 R)$ was also supported by the ${ }^{1} \mathrm{H}$ NMR spectra of 1 in $\mathrm{CD}_{3} \mathrm{OD}$ which was superimposable with those of (+)-epi-indolactam V (see Supplementary Information, Figure S25, Table S2) [28]. Thus, leading us to conclude that compound 1 was 12-epi-lyngbyatoxin A. This is the first report of 12-epi-lyngbyatoxin A (1) from the nature. Compound $\mathbf{1}$ had been obtained during the synthetic study of lyngbyatoxin A (2, teleocidin A-1) as one of the inseparable mixtures [20].

Figure 4. The structure of (-)-indolactam-V (6).

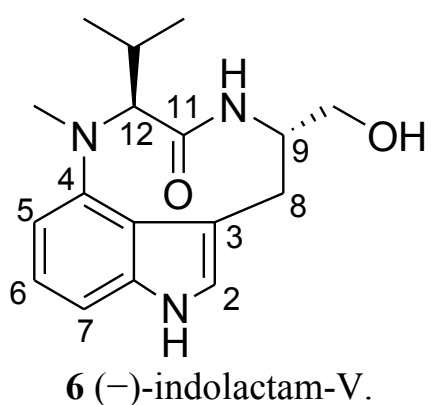

In cytotoxic assays using L1210 leukemia cells, the $\mathrm{IC}_{50}$ values of $\mathbf{1}$ and $\mathbf{2}$ were $20.4 \mu \mathrm{M}$ and $8.1 \mu \mathrm{M}$, respectively. The $\mathrm{IC}_{50}$ value of $\mathbf{1}$ was slightly higher than that of $\mathbf{2}$. Both compounds showed moderate cytotoxicity. Compound $\mathbf{2}$ was formerly reported to exhibit cytotoxic effects against HeLa and ACC-MESO-1 cells with $\mathrm{IC}_{50}$ of $35 \mu \mathrm{M}$ and $11 \mu \mathrm{M}$, respectively [32]. These values are comparable to the cytotoxic activities of $\mathbf{1}$ and $\mathbf{2}$ obtained in this study.

In the crustacean lethal activity tests using the shrimp Palaemon paucidens, both $\mathbf{1}$ and $\mathbf{2}$ showed similar lethal activities. The $\mathrm{LD}_{100}$ value of 1 was $7.5 \mathrm{mg} / \mathrm{kg}$, while 2 was $5 \mathrm{mg} / \mathrm{kg}$. Injection of 1 and 2 caused paralysis on the tested shrimp. Paralysis was not observed with compound $\mathbf{2}$ if the dose was less than the lethal amount. However, it was observed that compound $\mathbf{1}$ caused paralysis with a dose of $0.9 \mathrm{mg} / \mathrm{kg}$. These results may indicate that $\mathbf{1}$ and $\mathbf{2}$ have different toxicity pathways.

Lyngbyatoxin A (2, teleocidion A-1) and related compounds are known as potent tumor promoters [6]. These compounds bind to the cysteine-rich $\mathrm{C} 1$ domains $(\mathrm{C} 1 \mathrm{~A}$ and $\mathrm{C} 1 \mathrm{~B})$ of protein kinase $\mathrm{C}(\mathrm{PKC})$ isozymes to activate them, possibly leading to tumor formation. Affinities of the isolated compounds for $\mathrm{PKC} \delta$ using a synthetic $\mathrm{PKC} \delta$ - $\mathrm{C} 1 \mathrm{~B}$ peptide were evaluated by competition binding assay with $\left[{ }^{3} \mathrm{H}\right]$ phorbol 12,13-dibutyrate $(\mathrm{PDBu})$. The values of $K_{i}$ for the inhibition of $\left.{ }^{3} \mathrm{H}\right] \mathrm{PDBu}$-binding were $17 \mathrm{nM}$ and $0.11 \mathrm{nM}$ for $\mathbf{1}$ and 2, respectively. Aplysiatoxin (ATX) and debromoaplysiatoxin (DATX) are 12-O-tetradecanoylphorbol-13-acetate (TPA)-type tumor promoters which activate PKC as with lyngbyatoxin A (2) [6,29]. It was reported that $K_{i}$ values of ATX and DATX for binding to $\mathrm{PKC} \delta$-C1B are $0.41 \mathrm{nM}[35,36]$ and $0.20 \mathrm{nM}$ [37], respectively. These $K_{i}$ values are comparable to that of compound 2 obtained in this study. On the other hand, the affinity for PKC $\delta$-C1B binding of compound 1 was more than a hundred times weaker than that of compound 2. The results suggest the $\mathrm{C} 12$ configuration of the indolactam moiety of lyngbyatoxin A is very important for the binding with the PKC $\delta$-C1B peptide.

Our results showed the $K_{i}$ value for $\mathrm{PKC} \delta$-C1B peptide binding of lyngbyatoxin A (2) was similar to those of other PKC activators aplysiatoxin and debromoaplysiatoxin. Lyngbyatoxin A (2) has been reported to be a potent tumor promoter and have the ability to strongly induce PKC activity [6,7,29]. While 12-epi-lyngbyatoxin A (1) and lyngbyatoxin A (2) showed comparable cytotoxic and crustacean 
lethal activities, 12-epi-lyngbyatoxin A (1) had more than 100 times lower binding affinity for PKC compared to lyngbyatoxin A (2). The results revealed that the cytotoxic and lethal mechanism of lyngbyatoxin-type compounds might be mediated through a non-PKC activation pathway. In this connection, there was a report about no correlation between the cytotoxicity and ability to bind to and activate $\mathrm{PKC} \delta$ when examining the contribution of $\mathrm{PKC} \delta$ to the cytotoxicity of aplysiatoxin related compounds [38]. Therefore, other targets that offer alternatives to PKC isozymes might exist for the expression of toxic activities by lyngbyatoxin-type compounds. Further study is necessary to verify this hypothesis.

In addition, lyngbyatoxin A (2) was reported as the causative agent of human skin irritation and marine turtle poisoning $[3,8,9]$. Since the new lyngbyatoxin derivative (1) has the similar cytotoxicity and lethal activity with lyngbyatoxin A (2), it is supposed that 12-epi-lyngbyatoxin A (1) is also a causative agent possibly.

\section{Experimental Section}

\subsection{General Experimental Procedures}

HPLC was performed using a SHIMADZU HPLC (SHIMADZU Co., Kyoto, Japan) pump equipped with a SPD-M10A diode array detector. HR-ESI-MS spectra data were determined using Bruker micrOTOF QII (Bruker Co., Bremen, Germany) mass spectrometer. NMR spectra were recorded in $\mathrm{CDCl}_{3}$ at $800 \mathrm{MHz}$ and $200 \mathrm{MHz}$ for ${ }^{1} \mathrm{H}$ and ${ }^{13} \mathrm{C}$ on a Bruker AVANCE III $800 \mathrm{MHz}$ (Bruker Co., Bremen, Germany) spectrometer or in $\mathrm{CD}_{3} \mathrm{OD}$ at $600 \mathrm{MHz}$ for ${ }^{1} \mathrm{H}$ on a Bruker AVANCE III $600 \mathrm{MHz}$ spectrometer; the chemical shifts were reported in $\delta$ units (ppm) using $\mathrm{CDCl}_{3}$ solvent ( $\delta_{\mathrm{H}}$ at $7.3 \mathrm{ppm}$ and $\delta_{\mathrm{C}}$ at $77.2 \mathrm{ppm}$ ) or using $\mathrm{CD}_{3} \mathrm{OD}$ solvent $\left(\delta_{\mathrm{H}}\right.$ at $3.3 \mathrm{ppm}$ ) as the internal standard signals. Optical rotations were measured on a JASCO P-2100 series.CD spectra were measured on a JASCO J-715 (JASCO Co., Tokyo, Japan) and UV spectra were on a HITACHI U-3000 (Hitachi High-Tech Fielding Co., Tokyo, Japan) spectrometer.

\subsection{Marine Cyanobacterium Moorea producens}

Samples of a marine cyanobacterium, Moorea producens, were collected at Kahala Beach, Oahu island, Hawaii in 1998. After freeze-drying, samples were stored at $-30{ }^{\circ} \mathrm{C}$ until experiments were performed.

\subsection{Extraction and Isolation}

The dried sample ( $823 \mathrm{~g}$ dry wt.) was extracted twice with ethanol, six times with methanol and five times with acetone (see Supplementary Information, Figure S28). After evaporation of the solvents, the extracts were combined and partitioned between hexane and $80 \%$ methanol. The $80 \%$ methanol layer was again evaporated and partitioned with a mixture of ethyl acetate (EtOAc) and distilled water. The fraction of distilled water was then dissolved with butanol and separated into two extracts. The ethyl acetate fraction was then subjected to an open glass column $20 \times 300 \mathrm{~mm}$ packed with ODS resin (Pegasil Prep ODS, Senshu Co., Tokyo, Japan), with stepwise in 50\%, 70\%, 90\% and $100 \%$ methanol. Each eluted fraction was tested with crustacean lethal toxicity. The most toxic fraction 
eluted with $90 \%$ methanol (1220 mg dry wt.) was purified by reversed phase liquid chromatography on a $20 \times 250 \mathrm{~mm}$ column (SHISEIDO CAPCELL PAK-ODS, Shiseido Co., Tokyo, Japan) using an isocratic HPLC system (flow rate; $4 \mathrm{~mL} / \mathrm{min}$, detection; $190-800 \mathrm{~nm}$ ) with $82 \% \mathrm{MeOH}$ to yield the main toxic peak which was consisted with at least two compounds. A recycle chromatography HPLC system (system unit; Senshu Scientific SSC-1310 (Senshu Co., Tokyo, Japan), column; SHISEIDO CAPCELL PAK-ODS (Shiseido Co., Tokyo, Japan) $10 \times 250 \mathrm{~mm}$, solvent; 82\% MeOH, flow rate; $1 \mathrm{~mL} / \mathrm{min}$, detection; $210 \mathrm{~nm}$ ) was then utilized to completely isolate 12-epi-lyngbyatoxin A (1) $(2.8 \mathrm{mg})$ and lyngbyatoxin A (2) (10.2 $\mathrm{mg})$ from the main toxic fraction.

\subsection{2-Epi-Lyngbyatoxin A (1) and Lyngbyatoxin A (2)}

12-Epi-lyngbyatoxin A (1): Gummy solid; $[\alpha]^{\mathrm{D}}{ }_{18}=+85.5^{\circ}(c$ 0.12, MeOH); Circular dichroism $(\mathrm{CD}$, in $\mathrm{MeOH}),[\theta]_{212.5 \mathrm{~nm}}-2760,[\theta]_{215 \mathrm{~nm}} 970,[\theta]_{225 \mathrm{~nm}} 33,900,[\theta]_{235 \mathrm{~nm}} 41,200,[\theta]_{249.5 \mathrm{~nm}} 1650$, $[\theta]_{252.5 \mathrm{~nm}}-1650,[\theta]_{258 \mathrm{~nm}}-4100,[\theta]_{280 \mathrm{~nm}}-690,[\theta]_{310 \mathrm{~nm}} 1470,[\theta]_{330 \mathrm{~nm}} 630$ (Figure 3); UV $\lambda_{\max }(\mathrm{EtOH})$ $\mathrm{nm}(\log \varepsilon) 231$ (4.33), 301 (3.86); ${ }^{1} \mathrm{H}$ NMR (800 MHz, $\left.\mathrm{CDCl}_{3} ; 600 \mathrm{MHz}, \mathrm{CD}_{3} \mathrm{OD}\right)$ and ${ }^{13} \mathrm{C} \mathrm{NMR}$ $\left(200 \mathrm{MHz}, \mathrm{CDCl}_{3}\right.$ ) data; HRESIMS $m / z[\mathrm{M}+\mathrm{H}]^{+} 438.3070$ (calcd for $\mathrm{C}_{27} \mathrm{H}_{39} \mathrm{~N}_{3} \mathrm{O}_{2}, 437.3042$ ).

Lyngbyatoxin A (2): Gummy solid; $[\alpha]^{\mathrm{D}}{ }_{18}=-102.4^{\circ}$ (c 0.13, MeOH); Circular dichroism (CD, in $\mathrm{MeOH}),[\theta]_{215 \mathrm{~nm}}-660,[\theta]_{221.5 \mathrm{~nm}}-6550,[\theta]_{229.5 \mathrm{~nm}} 2670,[\theta]_{234 \mathrm{~nm}} 12,200,[\theta]_{237.5 \mathrm{~nm}} 2510,[\theta]_{257 \mathrm{~nm}}$ $-20,100,[\theta]_{298 \mathrm{~nm}}-790,[\theta]_{313 \mathrm{~nm}} 5520,[\theta]_{333 \mathrm{~nm}} 470$ (Figure 3); UV $\lambda_{\max }(\mathrm{EtOH}) \mathrm{nm}(\log \varepsilon) 230(4.46)$, 301 (3.98); ${ }^{1} \mathrm{H}$ NMR (800 MHz, $\mathrm{CDCl}_{3}$ ) and $\left.{ }^{13} \mathrm{C} \mathrm{NMR} \mathrm{(200} \mathrm{MHz,} \mathrm{CDCl}_{3}\right)$ data.

\subsection{Cytotoxicity Assay}

The cytotoxic activities of compounds $\mathbf{1}$ and $\mathbf{2}$ were tested toward L1210 mouse leukemia cells. The detailed methods were reported previously [39]. Differences with the reported methods [39] were (a) samples were dissolved with methanol; and (b) the methanol dissolved samples were applied onto each well and air-dried before the addition of L1210 cells.

\subsection{Crustacean Lethality Test}

The shrimp Palaemon paucidens (average weight, $0.5 \mathrm{~g}$ ) was used for the crustacean lethality test. Tested samples were suspended with 1\% Tween 20 (polyoxyethylene (20) sorbitan monolaurate). Two micro liter of each sample suspension was injected into the abdominal cavity of the shrimp ( $n=3-5$ ). The shrimp were monitored every $30 \mathrm{~min}$ for $4 \mathrm{~h}$. Through the lethality tests, the lethal dose $100 \%$ values $\left(\mathrm{LD}_{100}\right)$ were determined. One percent Tween 20 without sample was used as reference. $\mathrm{LD}_{100}$ was defined as weight of sample per unit weight of crustacean.

\subsection{Binding Assay of PKC Ligands Using PKC-C1B Peptide}

The binding of $\left[{ }^{3} \mathrm{H}\right] \mathrm{PDBu}$ to the $\mathrm{PKC} \delta$-C1B peptide was evaluated by the procedure of Sharkey and Blumberg [40] with modifications as reported previously [41,42] using $50 \mathrm{mM}$ tris-maleate buffer (pH 7.4 at $4{ }^{\circ} \mathrm{C}$ ), $13.8 \mathrm{nM} \mathrm{PKC} \delta$-C1B peptide, $20 \mathrm{nM}\left[{ }^{3} \mathrm{H}\right] \mathrm{PDBu}(18.7 \mathrm{Ci} / \mathrm{mmol}$, Perkin-Elmer Life Sciences), $50 \mu \mathrm{g} / \mathrm{mL}$ 1,2-dioleoyl-sn-glycero-3-phospho-L-serine (Sigma, St. Louis, MO, USA), $3 \mathrm{mg} / \mathrm{mL}$ bovine $\gamma$-globulin (Sigma, St. Louis, MO, USA), and various concentrations of inhibitors. 
The concentration of the properly folded $\mathrm{PKC} \delta$ - $\mathrm{C} 1 \mathrm{~B}$ peptide was estimated to be about $3 \mathrm{nM}$ on the basis of $B_{\max }$ values of Scatchard analyses reported previously [41,42]. Binding affinity was evaluated based on the concentration required to cause $50 \%$ inhibition of the specific binding of $\left[{ }^{3} \mathrm{H}\right] \mathrm{PDBu}$, the $\mathrm{IC}_{50}$, which was calculated with Microsoft Excel. The inhibition constant, $K_{i}$, was calculated by the method of Sharkey and Blumberg [40].

\section{Conclusions}

The lethal toxicity guided purification of an ethyl acetate extract from the cyanobacterium Moorea producens resulted in the isolation of lyngbyatoxin A (2) and a new compound 12-epi-lyngbyatoxin A (1). The absolute configuration of compound $\mathbf{1}$ was deduced from the analyses of the NMR, optical rotation and CD spectra. While 12-epi-lyngbyatoxin A (1) and lyngbyatoxin A (2) showed comparable cytotoxic and crustacean lethal activities, 12-epi-lyngbyatoxin A (1) had more than 100 times lower binding affinity for protein kinase $\mathrm{C} \delta$ compared to lyngbyatoxin A (2). This suggests that the cytotoxic and lethal mechanism of lyngbyatoxin-type compounds might be mediated through a non-PKC activation pathway.

\section{Acknowledgments}

This work was supported partly by JSPS Grant-in-Aid for Scientific Research Grant Number 24510294 (to Hiroshi Nagai).

\section{Author Contributions}

Hiroshi Nagai conceived and designed the research. Hiroshi Nagai and Kazuhiro Irie supervised the research. Hiroshi Nagai and Bryan Sakamoto contributed to the sample collection. Weina Jiang and Wei Zhou purified the compound. Ryuichi Watanabe, Toshiyuki Suzuki and Hajime Uchida performed the spectral measurement. Weina Jiang carried out the structural identification, toxicity assay. Masayuki Kikumori performed the binding assay. Weina Jiang, Kazuhiro Irie and Hiroshi Nagai analyzed the data and wrote the paper. Michiya Kamio and Bryan Sakamoto reviewed and edited the manuscript.

\section{Conflicts of Interest}

The authors declare no conflict of interest.

\section{References}

1. Engene, N.; Rottacker, E.C.; Kaštovský, J.; Byrum, T.; Choi, H.; Ellisman, M.H.; Komárek, J.; Gerwick, W.H. Moorea producens gen. nov., sp. nov. and Moorea bouillonii comb. nov., tropical marine cyanobacteria rich in bioactive secondary metabolites. Int. J. Syst. Evol. Microbiol. 2012, 62, 1171-1178.

2. Burja, A.M.; Banaigs, B.; Abou-Mansour, E.; Grant Burgess, J.; Wright, P.C. Marine cyanobacteria-Aprolific source of natural products. Tetrahedron 2001, 57, 9347-9377. 
3. Cardellina, J.H.; Marner, F.J.; Moore, R.E. Seaweed dermatitis: Structure of lyngbyatoxin A. Science 1979, 204, 193-195.

4. Moore, R.E.; Blackman, A.J.; Cheuk, C.E.; Mynderse, J.S.; Matsumoto, G.K.; Clardy, J.; Woodard, R.W.; Craig, J.C. Absolute stereochemistries of the aplysiatoxins and oscillatoxin A. J. Org. Chem. 1984, 49, 2484-2489.

5. Mynderse, J.S.; Moore, R.E.; Kashiwagi, M.; Norton, T.R. Antileukemia activity in the Osillatoriaceae: Isolation of debromoaplysiatoxin from Lyngbya. Science 1977, 196, 538-540.

6. Fujiki, H.; Mori, M.; Nakayasu, M.; Terada, M.; Sugimura, T.; Moore, R.E. Indole alkaloids: Dihydroteleocidin B, teleocidin, and lyngbyatoxin A as members of a new class of tumor promoters. Proc. Natl. Acad. Sci. USA 1981, 78, 3872-3876.

7. Fujiki, H.; Tanaka, Y.; Miyake, R.; Kikkawa, U.; Nishizuka, Y.; Sugimura, T. Activation of calcium-activated, phospholipid-dependent protein kinase (protein kinase C) by new classes of tumor promoters: Teleocidin and debromoaplysiatoxin. Biochem. Biophys. Res. Commun. 1984, 120, 339-343.

8. Yasumoto, T. Fish poisoning due to toxins of microalgal origins in the Pacific. Toxicon 1998, 36, 1515-1518.

9. Ito, E.; Satake, M.; Yasumoto, T. Pathological effects of lyngbyatoxin A upon mice. Toxicon 2002, 40, 551-556.

10. Nagai, H.; Yasumoto, T.; Hokama, Y. Aplysiatoxin and debromoaplysiatoxin as the causative agents of a red alga Gracilaria. coronopifolia poisoning in Hawaii. Toxicon 1996, 34, 753-761.

11. Nagai, H.; Yasumoto, T.; Hokama, Y. Manauealides, some of the causative agents of a red alga Gracilaria. coronopifolia poisoning in Hawaii. J. Nat. Prod. 1997, 60, 925-928.

12. Nagai, H.; Kan, Y.; Fujita, T.; Sakamoto, B.; Hokama, Y. Manauealide C and anhydrodebromoaplysiatoxin, toxic constituents of the Hawaiian red alga, Gracilaria Coronopifolia. Biosci. Biotechnol. Biochem. 1998, 62, 1011-1013.

13. Arthur, K.; Limpus, C.; Balazs, G.; Capper, A.; Udy, J.; Shaw, G.; Keuper-Bennett, U.; Bennett, P. The exposure of green turtles (Chelonia mydas) to tumour promoting compounds produced by the cyanobacterium Lyngbya. majuscula and their potential role in the aetiology of fibropapillomatosis. Harmful Algae 2008, 7, 114-125.

14. Harr, K.E.; Szabo, N.J.; Cichra, M.; Phlips, J.E. Debromoaplysiatoxin in Lyngbya-dominated mats on manatees (Trichechus manatus latirostris) in the Florida King's Bay ecosystem. Toxicon 2008, 52, 385-388.

15. Namikoshi, M.; Rinehart, K.L. Bioactive compounds produced by cyanobacteria. J. Ind. Microbiol. 1996, 17, 373-384.

16. Gademann, K.; Portmann, C. Secondary metabolites from cyanobacteria: Complex structures and powerful bioactivities. Curr. Org. Chem. 2008, 12, 326-341.

17. Molinski, T.F.; Dalisay, D.S.; Lievens, S.L.; Saludes, J.P. Drug development from marine natural products. Nat. Rev. Drug. Discov. 2008, 8, 69-85.

18. Sakai, S.I.; Hitotsuyanagi, Y.; Aimi, N.; Fujiki, H.; Suganuma, M.; Sugimura, T.; Endo, Y.; Shudo, K. Absolute configuration of lyngbyatoxin A (teleocidin A-1) and teleocidin A-2. Tetrahedron Lett. 1986, 27, 5219-5220. 
19. Aimi, N.; Odaka, H.; Sakai, S.I.; Fujiki, H.; Suganuma, M.; Moore, R.E.; Patterson, G.M.L. Lyngbyatoxins B and C, two new irritants from Lyngbya majuscula. J. Nat. Prod. 1990, 53, 1593-1596.

20. Muratake, H.; Okabe, K.; Natsume, M. Synthesis of teleocidins A, B and their congeners. Part 2. Synthesis of lyngbyatoxin A (teleocidin A-1), teleocidin A-2, pendolmycin, and $(R, E)$ - and $(S, E)$-7-(3,7,11-trimethyl-1,6,10-dodecatrien-3-yl)-(-)-indolactams V. Tetrahedron 1991, 47, $8545-8558$.

21. Endo, Y.; Shudo, K.; Okamoto, T. Molecular requirements for epigenetic modulators. Synthesis of active fragments of teleocidins and lyngbyatoxin. Chem. Pharm. Bull. 1982, 30, 3457-3460.

22. Irie, K.; Hirota, M.; Hagiwara, N.; Koshimizu, K.; Hayashi, H.; Murao, S.; Tokuda, H.; Ito, Y. The Epstein-Barr virus early antigen inducing indole alkaloids, (-)-indolactam-V and its related compounds, produced by Actinomycetes. Agric. Biol. Chem. 1984, 48, 1269-1274.

23. Fujiki, H.; Suganuma, M.; Nakayasu, M.; Tahira, T.; Endo, Y.; Shudo, K.; Sugimura, T. Structure-activity studies on synthetic analogues (indolactams) of the tumor promoter teleocidin. Jpn. J. Cancer Res. 1984, 75, 866-870.

24. Kawai, T.; Ichinose, T.; Takeda, M.; Tomioka, N.; Endo, Y.; Yamaguchi, K.; Shudo, K.; Itai, A. Prediction of ring conformations of indolactams. Crystal and solution structures. J. Org. Chem. 1992, 57, 6150-6155.

25. Sakai, S.I.; Aimi, N.; Yamaguchi, K.; Hitotsuyanagi, Y.; Watanabe, C.; Yokose, K.; Koyama, Y.; Shudo, K.; Itai, A. Elucidation of the structure of olivoretin A and D (teleocidin B). Chem. Pharm. Bull. 1984, 32, 354-357.

26. Endo, Y.; Shudo, K.; Furuhata, K.; Ogura, H.; Sakai, S.I.; Aimi, N.; Hitotsuyanagai, Y.; Koyama, Y. Synthesis of optically active teleocidin derivatives. Absolute configuration of teleocidin B and olivoretin A. Chem. Pharm. Bull. 1984, 32, 358-361.

27. Hitotsuyanagi, Y.; Yamaguchi, K.; Ogata, K.; Aimi, N.; Sakai, S.I.; Koyama, Y.; Endo, Y.; Shudo, K.; Itai, A.; Iitaka, Y. Elucidation of the structures of olivoretin B and C. Chem. Pharm. Bull. 1984, 32, 3774-3778.

28. Endo, Y.; Shudo, K.; Itai, A.; Hasegawa, M.; Sakai, S.I. Synthesis and stereochemistry of indolactam-V, an active fragment of teleocidins. Structural requirements for tumor-promoting activity. Tetrahedron 1986, 42, 5905-5924.

29. Fujiki, H.; Sugimura, T. New classes of tumor promoters: Teleocidin, aplysiatoxin, and palytoxin. Adv. Cancer Res. 1987, 49, 223-264.

30. Irie, K.; Kajiyama, S.-I.; Funaki, A.; Koshimizu, K.; Hayashi, H.; Arai, M. Biosynthesis of indole alkaloid tumor promoter teleocidins (I): Possible biosynthetic pathway of the monoterpenoid moieties of teleocidins. Tetrahedron 1990, 46, 2773-2788.

31. Irie, K.; Isaka, T.; Iwata, Y.; Yanai, Y.; Nakamura, Y.; Koizumi, F.; Ohigashi, H.; Wender, P.A.; Satomi, Y.; Nishino, H. Synthesis and biological activities of new conformationally restricted analogues of (-)-indolactam-V: Elucidation of the biologically active conformation of the tumor-promoting teleocidins. J. Am. Chem. Soc. 1996, 118, 10733-10743.

32. Izumikawa, M.; Khan, S.T.; Komaki, H.; Takagi, M.; Shin-ya, K. JBIR-31, a new teleocidin analog, produced by salt-requiring Streptomyces sp. NBRC 105896 isolated from a marine sponge. J. Antibiot. 2009, 63, 33-36. 
33. Pu, J.; Deng, K.; Butera, J.; Chlenov, M.; Gilbert, A.; Kagan, M.; Mattes, J.; Resnick, L. De novo synthesis of teleocidin B analogs. Tetrahedron 2010, 66, 1963-1972.

34. Irie, K.; Hagiwara, N.; Koshimizu, K. New probes for receptor analysis of tumor promoters synthesis of fluorescent derivatives of (-)-indolactam $\mathrm{V}$, the basic ring-structure of teleocidins. Tetrahedron 1987, 43, 5251-5260.

35. Nakagawa, Y.; Yanagita, R.C.; Hamada, N.; Murakami, A.; Takahashi, H.; Saito, N.; Nagai, H.; Irie, K. A simple analogue of tumor-promoting aplysiatoxin is an antineoplastic agent rather than a tumor promoter: Development of a synthetically accessible protein kinase $\mathrm{C}$ activator with bryostatin-like activity. J. Am. Chem. Soc. 2009, 131, 7573-7579.

36. Yanagita, R.C.; Kamachi, H.; Tanaka, K.; Murakami, A.; Nakagawa, Y.; Tokuda, H.; Nagai, H.; Irie, K. Role of the phenolic hydroxyl group in the biological activities of simplified analogue of aplysiatoxin with antiproliferative activity. Bioorg. Med. Chem. Lett. 2010, 20, 6064-6066.

37. Kikumori, M.; Yanagita, R.C.; Tokuda, H.; Suzuki, N.; Nagai, H.; Suenaga, K.; Irie, K. Structure-activity studies on the spiroketalmoiety of a simplified analogue of debromoaplysiatoxin with antiproliferative activity. J. Med. Chem. 2012, 55, 5614-5626.

38. Hanaki, Y.; Kikumori, M.; Ueno, S.; Tokuda, H.; Suzuki, N.; Irie, K. Structure-activity studies at position 27 of aplog-1, a simplified analog of debromoaplysiatoxin with anti-proliferative activity. Tetrahedron 2013, 69, 7636-7645.

39. Kawabata, T.; Lindsay, D.J.; Kitamura, M.; Konishi, S.; Nishikawa, J.; Nishida, S.; Kamio, M.; Nagai, H. Evaluation of the bioactivities of water-soluble extracts from twelve deep-sea jellyfish species. Fish. Sci. 2013, 79, 487-494.

40. Sharkey, N.A.; Blumberg, P.M. Highly lipophilic phorbolesters as inhibitors of specific $\left[{ }^{3} \mathrm{H}\right]$ phorbol 12,13-dibutyrate binding. Cancer Res. 1985, 45, 19-24.

41. Irie, K.; Oie, K.; Nakahara, A.; Yanai, Y.; Ohigashi, H.; Wender, P.A.; Fukuda, H.; Konishi, H.; Kikkawa, U. Molecular basis for protein kinase $\mathrm{C}$ isozyme-selective binding: The synthesis, folding, and phorbol ester binding of the cysteine-rich domains of all protein kinase $\mathrm{C}$ isozymes. J. Am. Chem. Soc. 1998, 120, 9159-9167.

42. Shindo, M.; Irie, K.; Nakahara, A.; Ohigashi, H.; Konishi, H.; Kikkawa, U.; Fukuda, H.; Wender, P.A. Toward the identification of selective modulators of protein kinase $\mathrm{C}$ (PKC) isozymes: Establishment of a binding assay for $\mathrm{PKC}$ isozymes using synthetic $\mathrm{C} 1$ peptide receptors and identification of the critical residues involved in the phorbolester binding. Bioorg. Med. Chem. 2001, 9, 2073-2081.

(C) 2014 by the authors; licensee MDPI, Basel, Switzerland. This article is an open access article distributed under the terms and conditions of the Creative Commons Attribution license (http://creativecommons.orsg/licenses/by/3.0/). 